\title{
FILOSOFIA DA EDUCAÇÃO BRASILEIRA, ORIGEM E IMPORTÂNCIA
}

\section{Leoni Maria Padilha Henning* Laura Maria dos Santos Maurano **}

Resumo: Este artigo é fruto de uma pesquisa bibliográfica, pautada no pensamento reflexivo deweyano, que teve como objetivo encontrar subsídios teóricos para analisar a origem $e$ a importância da Filosofia à Educação brasileira, enquanto atividade problematizadora voltada à mudança, devendo estar sempre vinculada à prática. Verificou-se que a Educação só passou a ser um problema para a Filosofia a partir da formação de professores com a implantação das escolas normais.

Palavras-chave: Filosofia. Educação. Formação de professores.

Resumen: Este artículo es el resultado de una investigación bibliografíca, basada en el pensamiento reflexivo de Dewey, que tenía como objetivo encontrar bases teóricas para analizar el origene y la importancia de la Filosofía a la Educación de Brasil, porque

\footnotetext{
" Professora orientadora, atuante no Departamento de Educação da UEL e coordenadora do Grupo de Pesquisa Positivismo e pragmatismo e suas relações com a Educação. Email: leoni.henning@yahoo.com

** Aluna Especial do Curso de Mestrado em Educação pela UEL e integrante do Grupo de Pesquisa Positivismo e pragmatismo e suas relações com a Educação - Londrina/PR. Especialista em Propaganda, Marketing e Publicidade pela UniFil - Londrina/PR. Especialista em Gestão de Pessoas pela UniFil Londrina/PR. Graduada em Administração pela UniFil - Londrina/PR. Graduanda em Pedagogia na UniFil Londrina/PR. E-mail: lauramaurano@hotmail.com
}

és una actividad "problematizadora" que apunta cambios, así siempre debe estar vinculada a la práctica. Se encontró que la educación sólo empesó a ser uno problema para la filosofía a partir de la formación de maestros con la implementación de las escuelas normales.

Palabras clave: Filosofía. Educación. Formación del profesorado.

\section{Introdução}

Pesquisar sobre a presença dos filósofos no cenário da intelectualidade brasileira "que pensa a Educação", sob uma abordagem reflexiva, é importante para entendermos a origem e a importância da Filosofia à Educação brasileira, enquanto aquela atividade que problematiza as questões gestadas no âmbito educacional $e$ enfrentadas pelos profissionais interessados pelo fenômeno "em situação própria da nossa realidade". Dewey ${ }^{3}$ esclarece que "[...] uma vez que a educação é o processo por intermédio do qual se podem operar as transformações necessárias, [...], conseguimos justificar a afirmação de que a

HENNING, Leoni Maria Padilha; MAURANO, Laura Maria dos Santos. Filosofia da educação brasileira, origem e importância. Revista Sul-Americana de Filosofia e Educação. Número 21: nov/2013-abr/2014, p. 47-71. 
filosofia é a teoria da educação e esta a sua prática deliberadamente empreendida" (DEWEY, 1979b, p. 365). Nesse sentido, entendemos que para construirmos uma visão lúcida do fenômeno educativo brasileiro, exigese igualmente a compreensão da Filosofia da Educação enquanto um saber elaborado neste contexto. Para a realização deste trabalho, procuramos operar por meio da análise reflexiva, própria do campo filosóficoeducacional, pautada em alguns textos de autores pontuais encontrados na trajetória da Filosofia e da Filosofia da Educação realizada no Brasil, cujo tratamento nos permite traçarmos algumas pistas do problema desde as suas origens. Percebemos, entretanto, que inicialmente muito raramente os filósofos no Brasil tomaram a Educação como seu problema central, nem mesmo, os problemas próprios da nossa realidade enquanto povo para as suas reflexões primeiras. Essa conquista foi acontecendo muito gradativamente.

Tendo dito isso, esclarecemos que partimos de algumas premissas para o desenvolvimento do estudo, a saber: 1) O pensamento brasileiro tem origens ocidentais, tendo importante contribuição inicial vinda da escolástica no que diz respeito ao tomismo, elemento trazido principalmente pelos portugueses, ao que mais tarde se somaram outras influências como o "empirismo mitigado", o ecletismo e o positivismo francês, dentre outras ao longo do processo; 2) o Positivismo influenciou fortemente a sociedade brasileira da inaugurada República, se constituindo num marco causador de importante reação por parte da instalada hegemonia católica, tendo engendrado motivos doutrinais incisivamente laicos e antimetafísicos, dentre outros; 3) a Educação "brasileira" começa efetivamente a ser problema para a Filosofia somente a partir da necessidade de formação dos professores (acho que assim neste caso ficaria melhor). Quanto a esse último ponto, questiona-se se, de fato, a origem da disciplina Filosofia da Educação brasileira estaria mesmo atrelada à preocupação com a formação de professores.

O objetivo estabelecido aqui é encontrar subsídios teóricos que nos permitam aferir acerca da origem $e$ importância da Filosofia enquanto um 
saber voltado à Educação brasileira. Porém, a análise dos múltiplos aspectos que envolvem este tema seria demasiado extensa para um artigo, por isso é necessário o recorte do objeto. Portanto, buscando encontrar informações satisfatórias para responder à questão proposta serão analisados os aspectos histórico-filosóficos que permeiam o tema. Para confirmar a importância dessa perspectiva, Nóvoa reforça o entendimento dizendo que "[...] as ciências humanas são históricas por natureza, tanto pelos seus objetivos como pelos seus modos de conhecimento (NÓVOA, 2007, p. 17).

\section{Fundamentos metodológicos}

Diante da necessidade de elucidar o questionamento desta pesquisa foi realizada uma análise bibliográfica, pautada no pensamento reflexivo ou pensamento correto de tradição deweyana, o qual é entendido como atividade humana inteligente, questionadora, investigativa, encadeada, coerente, conexa, racional, sujeita à prova, aspirante à conclusão, em oposição ao pensamento irreflexivo, incorreto, acrítico, solto, irrelevante.
Dewey diz que "Assim, um pensamento ou ideia é a representação mental de algo não presente, e pensar consiste na sucessão de tais representações" (DEWEY, 1979a, p. 15). Ao buscar encontrar os nexos das ideias explicativas encontradas na bibliografia, seguimos compondo a nossa compreensão sobre o problema.

Mesmo tendo consciência das limitações de tempo, espaço, objeto selecionado $e$ adequado às coordenadas aqui estabelecidas, buscamos refletir sobre as ideias mais relevantes ao desenvolvimento do tema, pois procurar se pautar neste pensamento e não praticar o exercício reflexivo ao longo desta pesquisa não seria propriamente operar por meio da reflexão crítica, mas somente reproduzirmos o que nos dizem os textos.

A título ilustrativo, cumpre observar que o pensamento proposto por Dewey partiu inicialmente da teoria naturalista darwiniana, sendo, portanto entendido como resultado da evolução biológica. Dewey se aproximou desta teoria para fundamentar o caráter ativo, inteligente, interativo e natural da atividade humana, a partir da adaptação dos organismos vi- 
vos ao ambiente. Para o autor "[...] pensar é pôr em ordem um assunto, com o fim de descobrir o que significa ou indica". E o "[...] pensamento não existe sem essa coordenação" (DEWEY, 1979a, p. 244). Esta afirmação se fundamenta na ideia de inteligência, necessária para haver a organização. Ao operar com a superação dos dualismos, o autor, não concebe a inteligência dissociada da ação, pois sempre procurou a superação dos dualismos impostos pela Filosofia Tradicional que os provocara, segundo o seu entendimento. Nesse sentido, pensar os problemas "práticos" da Educação (assim, categorizados) não seria algo incompatível ao trabalho genuinamente filosófico.

Enquanto ato contínuo, percebemos que a afirmação de Dewey referente ao pensar, nos remete a alguns questionamentos fundamentais para entendê-lo. Quem pensa - ser? O que pensa - conteúdo? Por que pensa - causalidade? Como pensa - método? Para que pensa - finalidade?

Logo vem à mente que quem pensa é um organismo vivo, um ser biológico, diferente, mas não independente do ser inanimado. Então $O$ que pensa este ser relaciona-se a outra questão subsequente, isto é, pensa sobre a sua existência, seus problemas, suas relações, suas possibilidades, suas limitações desafiadas pelas suas crenças estremecidas. Pensa porque tem necessidade de manter sua existência e conservar a vida, uma vez que a mudança contínua desafia as crenças estabelecidas. Nesta manutenção, é necessário dispender esforços para transformar as energias. Logo, como pensa diz respeito à maneira como utiliza os esforços para transformar essas energias em elementos favoráveis à sua conservação e, assim fazendo, promove empenho inteligente para se beneficiar das energias presentes no ambiente. Pensa para se desenvolver, crescer, se conservar, se comunicar, se satisfazer. Partindo do pressuposto de que sua constituição é física, química e psíquica, se ele pensa é porque há inicialmente movimento de energias. Se há este movimento há também interação entre os seres, num processo de ação e reação. Nesse sentido, diante de uma necessidade, o organismo se desequilibra, precisando reagir e promover esforço para retomar o seu 
estado anterior. Assim, diante da satisfação recupera o equilíbrio.

Por pensamento reflexivo deweyano (DEWEY, 1979a, p. 24 e 25) entende-se o método que parte de uma dúvida, de uma perplexidade ou de um problema. Esta dúvida estimula a investigação, a pesquisa $e$ a busca de material que esclareça e resolva o problema e resulte em conhecimento. Portanto, Dewey entende que "Pensar é o método de se aprender inteligentemente, de aprender aquilo que utiliza e recompensa o espírito" (DEWEY, 1979b, p. 167, grifos do autor). É por meio da atividade física e psíquica que conhecemos, encontramos problemas e soluções, transformamos o mundo. Assim, falarmos em investigar a Educação "brasileira" devemos considerar em que medida que os problemas efetivamente "brasileiros" conquistaram os interesses dos nossos filósofos.

Seguindo a perspectiva deweyana de análise, pontuamos ainda que o autor, acredita que a Educação não é um processo de preparação para a vida, mas constitui-se a própria vida na qual a atividade, o mundo da ação e da prática manifestam o que é característico do homem, um ser de experiências (DEWEY, 1979b, p. 1). Quais seriam, pois, as experiências do homem brasileiro, dentre as quais nos interessam as educativas, que foram problematizadas pela Filosofia Brasileira?

Vale registrar que o ser humano não é somente biológico, pois, histórico, cultural e social. Nesse panorama, destacamos a dimensão social do homem para dizer que Dewey defende a continuidade da vida social por meio da Educação, portanto, defende a sua função social, ou seja, "A educação é para a vida social aquilo que a nutrição $e$ a reprodução são para a vida fisiológica" (DEWEY, 1979b, p. 10). Anísio Teixeira, o filósofo da Educação brasileira conhecido como um grande porta-voz das ideias deweyanas em nosso país, acrescenta sobre a importância da experiência, pois, para ele, não existem soluções prontas para serem aplicadas absolutamente em qualquer situação. Afirma:

Crescer e desenvolver-se é, para o homem, aumentar em força de compreensão, força de realização e força de expansão. $\mathrm{Ne}$ nhuma dessas forças se efetiva, porém, sem que ele experimen-

Número 21: novembro/2013-abril/2014 
te antes dirigir, coordenar e comandar as próprias forças de seu desejo, do seu pensamento $e$ do seu corpo (TEIXEIRA, 2007, p. 32).

Se o individuo é social, que tipo de sociedade Dewey preconizava? "Uma democracia é mais do que uma forma de governo; é, essencialmente, uma forma de vida associada, de experiência conjunta e mutuamente comunicada" (DEWEY, 1979b, p. 93). Daí a importância de investirmos nos processos educativos, pois, como disse Teixeira: "[...] a educação e a sociedade são dois processos fundamentais da vida, que mutuamente se influenciam" (TEIXEIRA, 2007, p. 87, grifos do autor). Podemos dizer que a sociedade democraticamente preconizada é aquela em que há indivíduos capazes intelectualmente de contribuir para as transformações necessárias, visando ao bem comum e, isso, só pode acontecer por meio do pensamento reflexivo. Ou seja, por meio da inteligência que constrói debates organizados, evitando a luta armada, mas preconizando uma luta por meio da inteligência como força social.

Esta reflexão sobre os fundamentos metodológicos propostos nes- ta pesquisa, não esgota a teoria do pensamento reflexivo, mas acreditamos que contribui para esse exercício, para a justificativa do próprio tema $e$ problema do nosso interesse, visando suscitar no leitor o desejo de também investigar. Neste momento, o estudo se apoia na teoria como um meio para buscar compreender as relações de causa e efeito versadas no problema, ou seja, uma oportunidade de utilizar o conteúdo como instrumento de aprendizagem, compreendendo contudo que ele não deve significar um fim em si mesmo, como era próprio da escola tradicional, doutrinária, conteudista, memorística, autoritária, e que tinha como resultado a manutenção do status quo, oposta à escola vinculada às ideias deweyanas.

Entendemos que a análise reflexiva é o caminho apropriado para apreendermos criticamente o pensamento filosófico, pois Severino argumenta que "[...] não é sempre que o pensar filosófico se expressa explicitamente; muitas vezes ele se encontra implícito. Subjacente a outras formas de expressão cultural" (SEVERINO, 2007, p. 55). Assim, as manifestações 
filosóficas podem estar explícitas, implícitas ou pressupostas.

Procurando entender se, de fato, a origem da Filosofia da Educação brasileira estaria mesmo atrelada à preocupação com a formação de professores, a partir deste ponto, a tarefa é desvelar a história da constituição da disciplina em apreço, procurando respostas que satisfaçam à proposição deste artigo, ao menos neste momento.

\section{O pensamento filosófico ocidental}

Em Severino é possível entender que a cultura ocidental se desenvolveu a partir de três culturas mediterrâneas, quais sejam: judaísmo, cristianismo, helenismo. Este período se refere à preponderância da Grécia, ou cultura grega a partir do domínio de Alexandre, o Grande, que juntamente com sua expansão militar promove a fusão das origens da Grécia ocidental - Atenas e as da Grécia Oriental - Império Bizantino. Portanto, a visão de homem e de mundo e, ainda, a percepção da realidade são aspectos resultantes das inter-relações dessas culturas, pois esse autor acredita que "[...] essas concepções básicas dão conta das orientações que os homens buscaram imprimir em suas ações $e$ em sua história, justificando, ideologicamente o mais das vezes, as suas ações políticas" (SEVERINO, 2007, p. 45). Assim, no encontro dos romanos, judeus e gregos é que temos então localizado as raízes da cultura ocidental, conforme esclarecemos a seguir.

O judaísmo era uma religião, uma doutrina mística e teológica e uma cultura mediterrânea. Sua história está registrada no Velho Testamento. Acreditavam num só Deus, na continuidade histórica, na valorização do corpo, na coletividade e no "por vir". Era uma visão transcendente e essencialista. Já os gregos não acreditavam que estavam ligados a um Deus pessoal. Achavam que o universo só podia ser explicado por princípios racionais. $\mathrm{O}$ homem era o único responsável pelo seu destino e devia se adequar às exigências do universo. Porém, com a expansão do Império Romano as duas culturas se encontram e inicialmente se confrontaram, mas, na sequência, com o cristianismo, há a síntese cultural a partir de um movimento social e religioso, en- 
quanto dissidência do judaísmo. Foi, justamente, por meio do cristianismo, que esses princípios foram legados ao Ocidente. Severino explica que: "[...] a impregnação dos princípios filosóficos gregos no cristianismo foi profunda e radical [...] o Ocidente é filho do racionalismo grego" (SEVERINO, 2007, p. 50).

Posteriormente, após o fim do Império Romano, a Igreja Católica começou a desenvolver métodos pedagógicos para "civilizar" os novos bárbaros oriundos do norte da Europa. A base desses métodos era o pensamento grego. Severino faz referência a dois pensadores cristãos que participaram dessa reelaboração: Agostinho e Tomás de Aquino, sendo que "[...] o primeiro compatibilizando a teologia e a ética cristã com a filosofia platônica; o segundo fazendo o mesmo com a filosofia aristotélica" (SEVERINO, 2007, p. 51). Eis a detecção de um importante lastro para a cultura brasileira, uma vez que os jesuítas, nossos primeiros educadores, trazem tal filosofia, principalmente o tomismo, como base de suas ações educativas no Brasil.

\section{As raízes portuguesas $e$ francesas}

Mesmo que o homem possa definir períodos históricos, tais como, antiguidade, idade média, renascença, era da revolução, modernidade, contemporaneidade, para descrever seu desenvolvimento político, econômico, cultural e social, e ainda, esclarecer como os territórios foram conquistados e as noções foram constituídas, os diversos acontecimentos não se dão de forma linear em todos os países. Se a temporalidade não é linear, o espaço é demarcado por meio de atividades comuns: lutas $e$ acordos. Portanto, podemos dizer que, na história humana, a conquista territorial e a constituição das nações sempre foram marcadas por conflitos, guerras e pactos. A Filosofia busca compreender as relações de poder $e$ o avanço do homem nesse panorama social em termos de seu crescimento, desenvolvimento e participação ativa no contexto das nações. O papel da educação com o seu projeto formativo foi sempre buscado contribuir nesse contexto.

No estabelecimento da nação portuguesa e na demarcação do seu território, não foi diferente. Sua luta girava em torno das culturas: hebrai- 
ca (judaísmo), portuguesa, muçulmana (islamismo) e cristã-ocidental; e, suas vitórias eram atribuídas à autoridade divina, assim como expressa Paim ao relatar que "Na luta contra os mouros, com vistas à sua expulsão da península, acreditava-se que os portugueses eram ajudados pela intervenção direta da divindade" (PAIM, 2007, p. 4). Destacamos que a dominação árabe sobre a península ibérica, após a invasão moura, liga Portugal à África moura. E por "mouro" entende-se o nome que os espanhóis e portugueses costumavam usar para se referir aos árabes. Naturalmente essas influências acabariam chegando ao Brasil.

Entre os séculos XII e XIV, para Paim, chegava a termo a "[...] expulsão dos árabes e a independência de Castela, criando-se as bases para a conquista de outros territórios" (PAIM, 2007, p. 4 e 5). A Coroa Portuguesa tentou manter os judeus como seus servos, porém como eles não se sujeitavam, no final do século XV foram expulsos. Porém, foi proposta uma possibilidade aos que quisessem ficar no território, qual seja, o batismo forçado. Desse modo, surge em Por- tugal os chamados "cristão-novos" ou quais foram discriminados praticamente até a segunda metade do século XVIII, quando Pombal intervem revogando a lei que amparava tal disparate. São justamente aqueles pertencentes à categoria de cristãosnovos que vieram para a Colônia. Paim diz que "O processo histórico, antes resumido, reflete-se na filosofia, registrando-se três grandes tradições: hebraico-portuguesa, muçulmana $e$ cristã-ocidental" (PAIM, 2007, p. 5).

O período medieval, anterior àquele no qual fomos descobertos, mas cuja cultura influenciou até mais tarde a cultura portuguesa, trouxe uma Filosofia baseada na autoridade divina manifesta em algumas obras $e$ pensadores, e, esta era o critério para se conhecer a verdade. Assim, seu incipiente pensamento filosófico gira em torno dos temas teológico-cristãos sem permitir evocar qualquer tema de cunho nacional, necessário ao desenvolvimento de um estado liberal.

No alvorecer da modernidade, o pensamento filosófico português tenta romper com o tradicionalismo, porém mais do que um rompimento radical, era uma tentativa de se adequar ao 
racionalismo cartesiano, concepção filosófica moderna que reconhece a razão como fonte exclusiva de conhecimento, a qual entra em debate com o empirismo. No afã de superar a dominação religiosa surge não só a busca de liberdade como também a busca por um Estado laico, impulsionado pelo estabelecimento do protestantismo.

[...] em 1683, John Locke (1632/1704) refugia-se na Holanda, onde amadurece em seu espírito a doutrina do sistema representativo, garantia do êxito da Revolução Gloriosa de 1688 e marco decisivo do pensamento liberal. [...] E assim a modernidade viu nascer o espiritualismo, que encontrará o seu lugar entre a senda aberta pelo empirismo que acabará circunscrevendo-se a uma inquirição sobre a ciência - e o transcendentalismo kantiano. Os três vetores iriam transformar-se no que de efetivamente novo viria a ser criado pela Filosofia Moderna (PAIM, 2007, p. 6 e 7, grifos do autor).

Além das influências portuguesas, o pensamento brasileiro também foi influenciado pelo ecletismo francês, conforme pontua Paim:

A filosofia brasileira, embora visceralmente ligada à portuguesa, seguiu uma linha autônoma, onde sobressaia a influência do ecletismo francês que, ao invés de contribuir para fixar tradição espiritualista - e talvez por essa via reaproximando-nos da problemática a que daria preferência a filosofia portuguesa - levou ao contato com as correntes neokantianas. E este contato acabaria consolidando aquela diversidade original [sic] de interesses (PAIM, 2007, p. 7).

As bases desta diversidade também podem ser encontradas na herança místico-religiosa por ocasião da Independência do Brasil. Esta herança está relacionada diretamente com o legado iluminista do período pombalino. Paim argumenta que a tradição religiosa:

[...] era exclusivamente católica e tivera de se defrontar com culturas pouco articuladas, africana e aborigine. [...] De sorte que a expulsão dos jesuítas em meados do século XVIII deixaria a própria Igreja à mercê do ideário iluminista, concebendo-se mesmo uma instituição religiosa de ensino, o Seminário de Olinda, à imagem e semelhança da Universidade reformada por Pombal. A herança místicoreligiosa deixou, assim, de constituir ponto de referência da intenção racionalizadora (PAIM, 2007, p. 8).

Uma análise mais minunciosa, proposta para outros estudos, do segundo período da escolástica portuguesa e das marcas traçadas pelo empirismo mitigado iriam relevar as 
direções da filosofia brasileira, porém para completar o entendimento geral, destacamos:

A expulsão dos jesuítas, em 1759 , [...], cindiu de modo violento $e$ abrupto o pensamento nacional. Daí em diante e até a Independência, o interesse maior estará voltado de um lado para a formação meramente cientifica e, de outro, ao que se supõe em proporções deveras limitadas, pela frustração do empenho modernizador capitaneado por Pombal, para as idéias politicas trazidas à baila pelas Revoluções Americana e Francesa (PAIM, p. 10, grifos nossos).

Quais são os reflexos desta situação no pensamento filosófico? Foi necessário superar o desenvolvimento colonial, imperial e, finalmente, o republicano, pois à época dos jesuítas lançaram-se os alicerces da Educação, porém não foi o suficiente para emergir um pensamento filosófico propriamente brasileiro em relação à Educação. Havia muitas carências como a possibilidade de editar livros, a existência de uma Universidade, um Estado laico, portanto, o interesse filosófico era muito reduzido na Colônia:

Até os começos da segunda metade do século XVIII, a produ- ção de autores brasileiros equivale acerca de duzentos títulos. As obras literárias de cunho histórico ou descritivas, bem como as de índole didática, técnica ou filosófica, oscilam em torno de trinta. Toda a parcela restante poderia ser agrupada como apologética do denominado saber de salvação, em sua maioria na forma de sermões (PAIM, 2007, p. 18 e 19).

Com a expulsão dos jesuítas, a Igreja Católica foi deixada à mercê do ideário iluminista. O espiritualismo eclético despontou como uma concepção filosófica durante o Segundo reinado. A oposição tradicionalista impõe o debate acerca da fundamentação eclética da moralidade.

[...] O ecletismo permitia ainda manter vivo o debate em torno das questões mais palpitantes da filosofia, evitando, assim, todo risco de dogmatismo - de que seria vítima o espiritualismo católico [...] O ecletismo servira ainda para projetar a intelectualidade brasileira no cenário europeu como elemento dotado de autonomia e independência em relação à filosofia portuguesa. [...] A oposição ao ecletismo provinha de dois segmentos: $o$ cientificismo e o tradicionalismo. [...] Justamente esta é que iria arrastar os ecléticos brasileiros para a movediça problemática moral, [...] Assim, instados pelos tradicionalistas que os acusavam de minar as bases morais da sociedade ao menosprezar o papel da Igreja Católica, os ecléticos brasileiros são levados a Número 21: novembro/2013-abril/2014 
empreender esta discussão: como fundar a moral a partir do empirismo de Biran? (PAIM, 2007, p. 106, grifos nossos).

Eis o despontar de um novo desenho ao pensamento filosófico no Brasil, marcado por visões antimetafísicas e religiosas e crescente tendência ao cientificismo. Nesse sentido, o período contemporâneo da Filosofia viu nascer esforços na procura da subjetividade como superação ao cientificismo, aquele que levou à termo a metafísica. Para Paim, "Estrutura-se a contemporânea epistemologia, [...] Surge, [...], um patamar de contestação ao cientificismo, [...] Processo análogo tem lugar no Brasil com a reação ao positivismo na Escola Politécnica do Rio de Janeiro [...] Forma-se no país uma corrente neopositivista [...]" (PAIM, 2007, p. 265).

Anísio Teixeira (TEIXEIRA, 2007, p. 140) é categórico ao questionar o que resta à Filosofia e nos impõe a inquietação do exercício reflexivo ao longo da vida e da atuação profissional na docência. O que acaba por servir de argumento à nossa luta em defesa, impreterível e irrevogável, da Filosofia da Educação para a formação de professores. Não uma Filo- sofia descritiva dos fatos históricos desconexos e sem significados, trabalhada em uma ou outra disciplina, mas uma verdadeira busca pelo pensamento reflexivo para analisar as possibilidades de desenvolvimento humano e profissional do educador alheio aos vieses ideológicos e, para, sucitar debates éticos, estéticos, políticos, culturais e sociais neste âmbito, por uma Filosofia da Educação enquanto teoria geral da educação, como preconizava Dewey, o grande mestre de Anísio (DEWEY, 1979, p. 365).

\section{Primórdios da educação brasileira}

Conforme exposto, o pensamento moderno procedeu da visão de mundo grega e impregnou todo o ocidente, chegando ao Brasil por meio dos padres jesuítas, quando as expedições portuguesas aportam na Terra de Vera Cruz, animadas pela conquista de novos continentes. $\mathrm{Na}$ Educação, essa influência foi marcada por esses educadores da Companhia de Jesus, cuja expedição tinha a missão primeira de converter os nativos à fé católica, acreditando-se que a alfabetização era o melhor meio para 
catequizá-los, visando à mudança dos seus costumes e hábitos. Paim mostra os elementos filosófico-educacionais presentes em nossas origens:

A Ratio Studiorum fixa as normas tanto para os chamados estudos inferiores como para os de nível universitário. Os primeiros visavam proporcionar ao estudante conhecimentos sólidos das gramáticas latina e grega, habilitá-lo a escrever e a falar de modo erudito. [...] Consistia o curso superior em três anos de filosofia (Aristóteles) e quatro de Teologia (S. Tomás). A idéia básica defendida pela pedagogia da Companhia de Jesus era a da subordinação da filosofia à teologia (PAIM, p.13 e 14).

Tinha início formalmente a Educação brasileira, sendo que sua ação pedagógica foi marcada, então, pela escolástica, a qual expressava especialmente a matriz filosófica europeia oriunda das escolas monásticas cristãs influenciadas por Tomás de Aquino, cujo pressuposto de sua obra, da qual se destaca, a Summa Theologica, é a tentativa de conciliar o pensamento aristotélico com o cristão, gerando a filosofia do "ser". Cumpre lembrar que a Filosofia Cristã estava anteriormente já bem consolidada nos períodos iniciados com a fase apostólica, patrística e monástica, encontrando agora na escolástica um dos problemas que urgia o enfrentamento, o problema da conciliação da razão e fé.

Desse modo, em se tratando da Educação brasileira nos primórdios do período colonial, compreendido entre 1500 e 1821 e, no período imperial, de 1822 até 1881, observamos que tendo sido majoritariamente desenvolvida pelos jesuítas, se desenvolveu em grande parte sustentada pelos pressupostos teológicos contidos na Ratio Studiorum aos quais se somaram gradativamente outras influências cristãs provindas de outras congregações religiosas que se juntaram para realizarem o grande objetivo da formação do bom cristão. Assim, a visão filosófica desses períodos era essencialista, quer dizer, buscava-se compreender as Verdades Absolutas no que diz respeito ao entendimento do homem espiritual e criatura de Deus, aos valores perenes estabelecidos pela fé e razão católica, e os demais preceitos dogmaticamente postos. Para além dos acidentes e contingências, restava o que é necessário, essencial, substancial. Desse modo, implícita e profundamente impregna- 
da pelo pensamento escolástico tomista, o pensamento brasileiro do período constituía-se, na verdade, mais como uma ideologia do que Filosofia, pela impossibilidade da busca do novo, da instalação da dúvida frente aos dogmas. Severino destaca que "[...] a formação dos educadores bem como de seus educandos confundia-se com sua formação religiosa" (SEVERINO, 2000, p. 273, grifos nossos).

Tomando-se outros elementos aglutinadores para um perfil de dependência cultural, podemos indicar que toda essa tradição que se estende muito longamente em nossa história, como veremos adiante mesmo que de forma ainda parcial, gerou segundo muitos estudiosos, um processo de Educação acrítica, como é por exemplo apontada por Paulo Freire (1978) como Educação bancária, própria de um sistema de dominação. Nessa modalidade de Educação não se sustenta a perspectiva antropológica do homem-sujeito, do ser transformador que tem por característica o Ser Mais ou daquele que se volta para a conquista de patamares avançados de conscientização sobre sua realidade.
Desvio de rota no percurso do pensamento filosófico-educacional em formação

Além da vertente religiosa que influenciou a Educação brasileira, também houve a influência do Positivismo, merecedor de destaque. $\mathrm{O}$ francês Augusto Comte é considerado o criador de um Sistema que surgiu como desenvolvimento do Iluminismo, das crises social e moral do fim da Idade Média e do nascimento da sociedade industrial - processos esses que foram marcados pela Revolução Francesa. Considerado como Sistema de ideias Positivas que compreende o mundo a partir do conhecimento racional e empírico, o Positivismo estabelece que os saberes acumulados pela sociedade ocidental, sob perspectiva teológica e metafísica, não respondiam aos questionamentos do homem sobre o mundo, sendo somente a ciência, por meio da razão, aquela que podia ser apropriada para fazer isto. Desse modo, a ciência passa a ser entendida como a forma mais adequada para adquirir conhecimento seguro e confiável. Para Comte, o Positivo era o último e mais perfeito estado da humanidade, pois os dois Número 21: novembro/2013-abril/2014 
anteriores, o teológico e o metafísico, constituíam-se em estágios de conhecimento humano a serem superados, se quisermos atingir etapas de Progressos para a Humanidade. Por Positivo se entende aquilo que é real, tangivel, fato apreendido pela experiência, $e$ assim por diante.

Nesse sentido, com Severino podemos compreender que os positivistas brasileiros, inspirados nos ensinamentos de Comte, queriam adequar o país à modernidade, uma vez que o filósofo francês, "[...] queria reformar a sociedade realizando, uma reforma da inteligência. Para ele, a desordem social decorria da ignorância" (SEVERINO, 2007, p. 128). Ele acreditava, também, que o Estado devia manter a ordem visando à sociedade industrial, preconizando junto à ordem, o progresso", componentes do dístico da nossa bandeira nacional. O Positivismo influenciou não só a política, mas também a cultura brasileira como um todo, destacando-se a Educação e muitas ideias que engendraram proposições da Constituição Federal e simbologia nacional, por exemplo. O Positivismo se estabelece como uma Filosofia referência para a República, exercendo desse modo, muita influência no Brasil, pois se constituiu num alicerce doutrinário para a tomada filosófica de um novo tempo, ocupando este espaço, propondo mudanças e acreditando num Estado laico.

Logo após a I Guerra Mundial, a comunidade internacional não mediu esforços para se recuperar da devastação da guerra, porém o Brasil somente a partir de 1930 entra em um processo de modernização econômica, política, cultural e científica. É a fase conhecida como Revolução Industrial acompanhada pelo processo de urbanização. Neste período, a Filosofia da Educação manifesta-se mais com uma postura implícita presente nos sistemas filosóficos, se contrapondo à da ideologia religiosa do catolicismo. Junta-se a essa vertente outras Filosofias anti-metafísicas, modernizadoras e progressistas. Severino salienta que:

[...] não é outro o sentido da intervenção teórica dos "Pioneiros da Educação", que já se pronunciavam com os seus discursos tematizadores buscando "praticar" uma reflexão, de cunho filosófico, sobre a educação, posicionando-se mediante categorizações teóricas, sobre o 
sentido da educação [...], também pretendem construir uma ciência da educação, livrando-a do monopólio explicativo até então mantido pela metafísica neotomista e cristã (SEVERINO, 2000, p. 281 e 282).

Portanto, neste momento começam as elaborações de concepções filosóficas sobre a Educação em busca de sentido e, agora, entendendo a Filosofia da Educação como um processo. Trata-se de uma fase mais explícita da Filosofia da Educação, na qual começa uma amplificação temática e uma legitimação, como exercício pertinente e válido do conhecimento humano, relacionado com a Educação, uma busca de identidade. Daí em diante, há um aumento significativo de produção científica, abrindo cada vez mais caminhos para as discussões da área. Uma nova visão humanista se coloca, destituída da perspectiva metafísica essencialista, defendendo antes a existência ao invés de uma essência definidora do ser humano. Atualmente, a visão essencialista, marcante dos períodos colonial e imperial no Brasil, parece estar superada como hegemonia, mas ainda presente no pensamento de alguns dos seus adeptos. O pensamento filo- sófico vem tomando nos dias de hoje, um caráter imanente em relação à realidade humana, numa perspectiva mais antropológica. Como explica Severino: "[...] agora a construção da história é responsabilidade exclusiva dos homens: não se trata mais de construir a Cidade de Deus, mas a polis, a cidade dos homens" (SEVERINO, 2000, p. 285, grifos do autor). Assim as abordagens filosóficas da Educação assumem a condição histórica e social da existência humana.

\section{A formação de professores como pro- blema filosófico}

Considerando a disciplina Filosofia da Educação entendemos que esta deveria ser o âmbito do pensamento livre. Mas, observamos pelo já exposto, que não foi isso o que ocorreu no Brasil em suas origens. Chegou cheia de impregnações ideológicas. Assim, o seu surgimento não ocorreu sob o pensamento crítico, questionador, exigente, mas sim sob um pensamento que só perpetuava a situação vigente, o poder da Igreja $e$ do Estado. A disciplina era desenvolvida simplesmente como elemento de ensino de conhecimentos dogmáticos, 
não promovendo questionamentos sobre si mesma e sobre os fins da Educação "brasileira".

O enfrentamento dos problemas próprios da educação em nossa cultura careceu de pesquisa e de estudos sérios de base científica e filosófica e, assim, a reflexão sobre os problemas educacionais "brasileiros" como base do ensino constituiu-se em situação de atraso para o avanço da situação educacional. Em referência às origens da nossa cultura, diz Severino que: "A situação é até compreensiva, pois a incorporação da cultura filosófica no país é feita de maneira dogmática, autoritária e ideologizada, sob formato escolasticizado" (SEVERINO, 2000, p. 275).

Até a instalação da nossa República em 1889, a preocupação com a formação profissional dos educadores acompanhada por uma reflexão consistente sobre a Educação era insignificante. Ou seja, até o início do século $\mathrm{XX}$ não se pode falar em Filosofia da Educação propriamente dita, pois havia mais referências aos pressupostos ideológicos e às posturas filosóficas implícitas nas práticas do que uma construção teórica debruçada às questões educacionais no território brasileiro. A alusão propriamente dita referente à Filosofia da Educação, enquanto disciplina, só vai aparecer efetivamente no Brasil a partir do início das Escolas Normais. Mas isso ainda de modo tímido, considerando os enormes problemas da educação brasileira como, por exemplo, seu frágil "sistema" para o atendimento da população, com índices de analfabetismo assustador, mesmo já na República, como também, a alta quantidade de professores leigos para a realização de um trabalho com déficit profissional. A criação da primeira Escola data de 1835, em Niterói, no Rio de Janeiro, com o objetivo de formar professores para o magistério, perpassando todo o período republicano.

É nos currículos das Escolas Normais que surge o componente curricular designado como Filosofia da Educação e é nesse espaço institucional da formação do magistério que a Filosofia da Educação adentra o ensino e a cultura pedagógica nacional (SEVERINO, 2000, p. 273, grifos nossos).

Posteriormente, a disciplina Filosofia da Educação aparece pela primeira vez no ensino superior atre- 
lada à criação das "[...] seções de Pedagogia das Faculdades de Filosofia e, mais tarde, das próprias Faculdades de Educação [...]", como afirmou o autor (SEVERINO, 2000, p. 274). Embora as perspectivas filosófico-educacionais mudem ao longo do tempo, a Filosofia foi ganhando espaço e demarcando sua importante contribuição à educação, tanto que a formação de professores já teve seu locus principal nas próprias faculdades de Filosofia, conforme preconizava a Lei 4.024 que fixou as Diretrizes e Bases da Educação Nacional em 1961, nos seguintes artigos:

Art. 59. A formação de professores para o ensino médio será feita nas faculdades de filosofia, ciências e letras [...]. Art. 116. Enquanto não houver número suficiente de professores primários formados pelas escolas normais ou pelos institutos de educação e sempre que se registre esta falta, a habilitação ao exercício do magistério, a título precário e até que cesse a falta, será feita por meio de exame de suficiência realizado em escola normal ou instituto de educação oficiais, para tanto credenciados pelo Conselho Estadual de Educação (BRASIL, PRESIDÊNCIA DA REPÚBLICA, Lei 4.024, de 20 de dezembro de 1961, grifos nossos).
Porém, o alvorecer de uma postura mais questionadora para a Filosofia da Educação é fenômeno bem recente, creditado aos Programas de Pós-Graduação stricto sensu que tem a pesquisa como instrumento fundamental e obrigatório para seu desenvolvimento. Neste contexto, é imprescindível mencionar o Programa de Filosofia da Educação da PUC/SP, pois:

Este Programa surgiu por iniciativa do professor Joel Martins [...], a partir da década de 1970. [...] preocupado com a abertura de uma frente em Filosofia da Educação, sob outras aspirações que não fossem aquelas da escolástica tomista que ainda prevalecia no Departamento de Filosofia da Universidade [...] (SEVERINO, p. 2000, 276).

Outro impulso importante foi a criação de um Grupo de Trabalho em Filosofia da Educação no quadro institucional da Associação Nacional de Pesquisa e Pós-graduação em Educação, a ANPED. Isso impulsionou significativamente a área, pois a ANPED é uma associação voltada à produção científica e avaliação de pesquisas educacionais no país, sendo mesmo referência internacional sobre os as- 
suntos gestados no âmbito dos estudos sobre Educação.

Nessa discussão, entretanto, vale considerar igualmente, os entraves e dificuldades que a própria Educação ofereceu, ao longo de sua história, ao aprimoramento dos estudos filosóficos, mesmo que entendamos as várias limitações que apresentava, muitas das quais, fora de seu próprio controle. Cumpre assim lembrar quando, no âmbito educacional foram coibidas iniciativas impulsionadoras da cultura filosófica que podiam vicejar nessa esfera, como é o caso, da tardia fundação das universidades em terras brasileiras e da pesquisa que tem neste âmbito o lugar par execellence para a promoção da curiosidade investigativa; da difícil aceitação e boa acolhida da disciplina nas escolas, resultando disso, a formação de bons profissionais no campo da Filosofia, quiçá, interessados no problema da Educação brasileira.

Superando, mesmo que em parte, uma tradição dificultosa para $\mathrm{o}$ florescimento de um genuíno espírito filosófico entre nós, devemos reconhecer que uma análise da legislação educacional, por exemplo, pode indi- car que, atualmente, os fundamentos filosóficos são pressupostos legais para o exercício da docência no nível básico, pois o artigo 62 da Lei de Diretrizes e Bases da Educação Nacional de 1996 dispõe que a "[...] formação de docentes para atuar na educação básica far-se-á em nível superior, em curso de licenciatura, [...]" e o artigo 11 da Resolução do Conselho Nacional de Educação que instituiu as Diretrizes Curriculares Nacionais para a Formação de Professores da Educação Básica, diz que:

Os critérios de organização da matriz curricular, [...] se expressam em eixos em torno dos quais se articulam dimensões a serem contempladas, na forma a seguir indicada: V - eixo articulador dos conhecimentos a serem ensinados e dos conhecimentos filosóficos, educacionais e pedagógicos que fundamentam a ação educativa. (BRASIL, RESOLUÇÃO $\mathrm{CNE} / \mathrm{CP} 1$, de 18 de fevereiro de 2002. Diretrizes Curriculares Nacionais para a Formação de Professores da Educação Básica, em nível superior, curso de licenciatura, de graduação plena, grifos nossos).

O mesmo já não acontece na docência de nível superior, pois o artigo 66 da mesma Lei só diz que "[...] a preparação para o exercício do 
magistério superior far-se-á em nível de pós-graduação, prioritariamente em programas de mestrado e doutorado" (BRASIL, PRESIDÊNCIA DA REPÚBLICA, Lei 9.394, de 20 de dezembro de 1996), porém mesmo que as DCN's de alguns curso de graduação preconizem a importância dos fundamentos filosóficos, isso não é consenso geral.

A análise dos dispositivos legais não nos satisfaz, todavia, porque entendemos que a disciplina Filosofia da Educação se caracteriza como pensamento reflexivo vinculado à prática, como atividade humana inteligente, indispensável à investigação. Por isso, a importância do aprender a aprender, enquanto um hábito correto, ativo, indagativo e operante, o aprender a partir e pela experiência como aspectos associados à formação de professores.

[...] fazer uma associação retrospectiva e prospectiva entre aquilo que fazemos às coisas $e$ aquilo que em conseqüencia essas coisas nos fazem gozar ou sofrer. Em tais condições a ação torna-se uma tentativa; experimenta-se o mundo para se saber como ele é; o que sofrer em conseqüência torna-se instrução - isto é, a descoberta das relações entre as coisas. O pensa- mento ou a reflexão, [...], é o discernimento da relação entre aquilo que tentamos fazer $e$ o que sucede em conseqüência. Por outras palavras - pensar é o esforço intencional para descobrir as relações específicas entre uma coisa que fazemos e a conseqüência que resulta, de modo a haver continuidade entre ambas (Dewey, 1979b, p. 152 a 164, grifos do autor e nossos).

O estágio inicial do ato de pensar é experiência. Esta observação pode figurar-se sovado lugar-comum. Deveria ser; mas infelizmente não é. Pelo contrário, o ato de pensar é com freqüencia considerado na teoria filosófica e na prática educativa como alguma coisa independente da experiência e capaz de ser cultivado isoladamente. (DEWEY, 1979b, p. 168, grifos nossos).

Mesmo que os dispositivos legais supracitados preconizem a importância dos fundamentos filosóficos ao exercício docente no nível básico, caberia investigarmos como isso tem ocorrido na prática. Neste sentido, estando alheios a uma Filosofia da Educação, propriamente dita, como poderiam os professores tomar consciência da realidade brasileira, problematizá-la, instaurar transformações substanciais nas ações pedagógicas embasados num espírito mais reflexivo, se formados a partir, muitas vezes, dos fundamentos de uma Educação Número 21: novembro/2013-abril/2014 
Tradicional, doutrinária, passiva, conteudista, memorística, autoritária, elitista, que visa à manutenção do status quo, oposta a uma proposta mais inovadora de uma educação mais crítica, ativa, transformadora, social, democrática, que busque a autonomia do educando, orientando a sua formação, provendo as condições para que estes possam refletir sobre a sua realidade, antever problemas $e$ propor soluções?

Assim, dando sequência à análise, percebemos que uma vez sendo uma das funções da pesquisa o impulsionar mudanças nas condições atuais buscando subsídios para intervenções, empreendemos esforços para que, a princípio, entendamos a realidade que está posta para que possamos deixar a nossa contribuição.

Considerando o que até aqui expusemos e dando continuidade às nossas inquietações, ao pesquisar se esta disciplina está atrelada às linhas que tratam sobre a formação de professores nos Programas de PósGraduação stricto sensu em Educação da região sul, no período compreendido entre 07 e 30 de junho de 2013, em meio virtual, a partir do site e dos critérios da Coordenação de Aperfeiçoamento de Pessoal de Nível Superior - Capes, encontramos uma realidade bem diferente, pois descobrimos que, de fato, a disciplina não está alocada juntamente com as linhas que tratam sobre a formação docente. E, quando aparece, está na linha da História da Educação. Sendo que nos nove Programas do Paraná, a disciplina Filosofia e Educação faz parte de somente um dos Programas pesquisados, e está alocada em linha separada da linha que trata especificamente sobre a formação de professores. Nos outros Programas a disciplina não aparece, embora a reflexão filosófica possa se dar em disciplinas como ética, epistemologia e outras. Já nos treze Programas do Rio Grande do Sul, a disciplina aparece somente em um Programa, nos outros não consta, porém um deles tem uma linha intitulada como Filosofia e História da Educação, onde as reflexões filosófico-educacionais são estudadas. E, ainda, aparecem disciplinas como Teorias da Educação com o objetivo de estudar as epistemologias que fundamentam a prática docente e, a Filo- 
sofia aparece também na linha Teorias e Culturas em Educação, em um dos Programas. Nos onze Programas de Santa Catarina, a disciplina Filosofia e Educação não consta, porém em um deles consta uma linha de pesquisa intitulada Filosofia da Educação.

Finalizando, retomanos o exposto na sessão sobre princípios metodológicos conforme Dewey, para dizer que esta pesquisa sinalizou a complexidade da problemática envolta neste tema e, por isso, nos deparamos com outras indagações que nos instigam a continuar pesquisando, pois a:

[...] origem do pensamento é alguma perplexidade, confusão ou dúvida. Para pensar verdadeiramente bem, cumpre-nos estar dispostos a manter e prolongar êsse estado de dúvida, que é o estímulo para uma investigação perfeita, na qual nenhuma idéia se aceite, nenhuma crença se afirme positivamente, sem que se lhes tenham descoberto as razões justificativas. (DEWEY, 1979a, p. 24 e 25)

Portanto, a pesquisa continuará em momento oportuno, para entendermos porque uma disciplina que adentrou o ensino por meio dos currículos das Escolas Normais, visando contribuir com a formação para o exercício do magistério se encontra, atualmente, separada das linhas que tratam sobre a formação de professores nos Programas Pós-Graduação stricto sensu em Educação brasileiros? Este fato caracteriza um dualismo entre entre teoria e prática neste âmbito? Esta separação teria suas origens mais remotas de nossa cultura no pensamento grego, como apontam alguns autores; nas filosofias que separavam a experiência do conhecimento, que não primavam pela educação como um fim em si mesma, e, que tinham como consequência a separação de classes, de um lado a elite intelectual e de outro os técnicos desconexos com a sua realidade social? Portanto, quais seriam as implicações do não reconhecimento da ligação estreita entre Filosofia da Educação e formação de professores?

\section{Considerações finais}

Operando com uma proposta de análise reflexiva a partir da abordagem histórico-filosófica da Educação no Brasil, encontramos em nossa pesquisa bibliográfica, que a cultura brasileira, porque ocidental, se desenvolveu a partir da fusão de elementos vindos do judaísmo, do helenismo e 
do cristianismo (SEVERINO, 2007, p. 45 a 51). Com a colonização, sabemos que o pensamento filosóficocristão se instala no Brasil por meio das ações educativas dos padres jesuítas. Este foi o início formal da Educação brasileira, marcado por uma concepção filosófica claramente escolástica. É importante lembrar que a escolástica, sendo de origem europeia, oriunda das escolas monásticas cristãs e sendo fortemente influenciada por Tomás de Aquino, nos oferece subsídios para afirmarmos a origem da Educação brasileira como tendo sido formada nesta tradição. Nesse sentido, entendemos que a primeira premissa possa ser considerada verdadeira.

Posteriormente, no período da industrialização, não só a sociedade brasileira, mas também a cultura e a Educação foram influenciadas pelo Positivismo, que se junta às ideias otimistas próprias do alvorecer da República brasileira com promessas de mudanças e crença num Estado laico, industrial e moderno, em oposição à hegemonia católica. Depreende-se ainda que o Pragmatismo contribui nessa perspectiva modernizado- ra, subordinando a verdade à utilidade da ação/pensamento eficaz, solucionadora de problemas cujo procedimento possa instigar o crescimento e o desenvolvimento; reconhecendo com isso a importância do fazer, da prática; defendendo uma modalidade de Educação conhecida como progressiva. A utilidade passou a ser um valor emblemático que estabeleceu que aquilo que importa é o que é útil e eficaz no sentido do que é necessário, que melhor organiza a vida visando construir uma sociedade melhor.

Percebemos ainda à luz da própria história que a terceira premissa também pode ser considerada verdadeira, pois a Educação só passou a ser um problema para a Filosofia brasileira a partir da "formação de professores" com a implantação das escolas normais ainda no século XIX. Foi nessa ocasião que o problema da Educação gerou séria preocupação, instituindo o início efetivo da disciplina Filosofia da Educação em nosso país. Portanto, procurando responder à preocupação central deste trabalho, constatamos que a origem da Filosofia da Educação brasileira está sim 
atrelada à preocupação com a formação de professores, fato que gerou outras dificuldades - tema para ser desenvolvido em outra oportunidade.

Até os dias atuais este aspecto tem sido um dos mais investigados pela Filosofia da Educação, por se tratar de campo fértil para pesquisa. Pois, a reflexão filosófica é exercida sobre algum aspecto da realidade concreta que desperta o interessa da disciplina (a Filosofia), neste caso, no que diz respeito à formação de professores. Trata-se de um campo imprescindível porque antevê, ou seja, avalia as possíveis consequências das ideias na prática docente, fornece ao educador subsídios para pensar sua prática com rigor, dando sentido à sua realidade de acordo com uma determinada visão de mundo, intencionalizando, questionando concep- ções, contribuindo para a resolução de problemas e transformando a realidade.

Por meio da análise dos Programas de Pós-Graduação stricto sensu em Educação foi possível verificar que os fundamentos de cunho filosófico presente nestes Programas estão restritos vinculados às Teorias Educacionais, à Epistemologia e à Ética, denotando a carência de fundamentos filosóficos efetivos às pesquisas em educação. As linhas de pesquisas destes Programas versam, principalmente, em torno da História e Historiografia; Ensino e Aprendizagem; Formação e Trabalho ou Ação Docente; Políticas; e, Inclusão escolar. Nesse sentido, esperamos instigar estudos que versem sobre aspectos dessa importante disciplina para a formação docente, a Filosofia da Educação.

\section{REFERÊNCIAS}

Brasília. Capes. Cursos Recomendados. Disponível em $<$ http://www.capes.gov.br/cursos-recomendados $>$ Acesso em: 07 a 30 de jun.2013. 
Brasília. Ministério da Educação e Cultura. Legislação Educacional. Disponível em <http://portal.mec.gov.br> Acesso em: 15 de jul.2013.

DEWEY, John. Como pensamos como se relaciona o pensamento reflexivo com o processo educativo: uma reexposição. Trad. Haydée Camargo Campos. $4^{\mathrm{a}}$ ed. São Paulo: Companhia Editora Nacional, 1979a. Atualidades Pedagógicas. Vol. 2.

Democracia e Educação: introdução à filosofia da educação. Trad. Godofredo Rangel e Anísio Teixeira. $4^{a}$ ed. São Paulo: Companhia Editora Nacional, 1979b. Atualidades Pedagógicas. Vol. 21.

FREIRE, Paulo Reglus Neves. Pedagogia do Oprimido. $5^{\text {a }}$ ed. Rio de Janeiro: Paz e Terra, 1978.

NÓVOA, Antonio. Por que história da educação. IN: STEPHANOU, Maria. BASTOS, Maria Helena Camara. (Orgs.) Histórias e memórias da educação no brasil. Vol. III - Século XX.

PAIM, Antônio. Histórias das ideias filosóficas no Brasil. $6^{a}$ ed. Vol. II. Salvador: Humanidades. 2007.

SEVERINO, Antonio Joaquim. Filosofia. 2a ed. São Paulo: Cortez, 2007.

A Filosofia da Educação no Brasil: esboço de uma trajetória. In: GHIRALDELLI, Paulo Junior. O que é filosofia da educação. $2^{a}$ ed. Rio de Janeiro: DP\&A, 2000.

TEIXEIRA Anísio. Pequena introdução à filosofia da educação. A escola progressista ou a transformação da escola. Rio de Janeiro: Editora UFRJ, 2007.

Recebido em 06/08/2013

Aprovado em 18/12/2013 